\title{
Precise Detection of Direct Glomerular Input Duration by the Olfactory Bulb
}

\author{
Anan Li, ${ }^{1,2}$ David H. Gire, ${ }^{3}$ Thomas Bozza, ${ }^{4}$ and Diego Restrepo ${ }^{1}$ \\ ${ }^{1}$ Department of Cell and Developmental Biology, Neuroscience Program and Rocky Mountain Taste and Smell Center, University of Colorado Anschutz \\ Medical Campus, Aurora, Colorado 80045, ${ }^{2}$ Wuhan Institute of Physics and Mathematics, The Chinese Academy of Sciences/State Key Laboratory of \\ Magnetic Resonance and Atomic and Molecular Physics, Wuhan, China 430071, ${ }^{3}$ Department of Molecular and Cellular Biology, and Center for Brain \\ Science, Harvard University, Cambridge, Massachusetts 02138, and ${ }^{4}$ Department of Neurobiology, Northwestern University, Evanston, Illinois 60208
}

Sensory neuron input to the olfactory bulb (OB) was activated precisely for different durations with blue light in mice expressing channelrhodopsin-2 in olfactory sensory neurons. Behaviorally the mice discriminated differences of 10 ms in duration of direct glomerular activation. In addition, a subset of mitral/tufted cells in the $\mathrm{OB}$ of awake mice responded tonically therefore conveying information on stimulus duration. Our study provides evidence that duration of the input to glomeruli not synchronized to sniffing is detected. This potent cue may be used to obtain information on puffs in odor plumes.

Key words: olfactory; puffs

\section{Introduction}

Duration is an important parameter of sensory stimuli extensively studied in both the visual and auditory systems (B.G. Cleland et al., 1971; Ikeda and Wright, 1974; Ehrlich et al., 1997; Klink and Klump, 2004). In the olfactory system the role of stimulus timing is not as well understood, but a recent study found precise detection of location of the onset of a stimulus within the sniff (sniff phase; Smear et al., 2011). Importantly, temporal properties of the stimulus are key for obtaining information from odor plumes found when an odor is released in the environment (Cardé and Willis, 2008; Park et al., 2014). In particular, because of turbulence, odors are unevenly distributed within odor plumes with odor containing eddies interspersed within air below behavioral threshold (odor puffs; Cardé and Willis, 2008). Furthermore, studies in insects have shown that stimulus duration is processed in the antennal lobe in invertebrates (Christensen and Hildebrand, 1997; Heinbockel et al., 1999).

However, although olfactory stimulus duration may be detected by humans (Frasnelli et al., 2006), no study has explored behavior and neuronal processing for discrimination of input duration by the mammalian olfactory system because of difficulty in studies due to the fact that input duration is affected by

Received Aug. 13, 2014; revised 0ct. 7, 2014; accepted 0ct. 15, 2014.

Author contributions: A.L., D.H.G., T.B., and D.R. designed research;A.L.,D.H.G., and T.B. performed research;T.B. contributed unpublished reagents/analytic tools; A.L., D.H.G., and D.R. analyzed data; A.L. and D.R. wrote the paper.

This work was supported by the Optogenetics Pilot Program and funded by the National Institutes of Health/ National Institute on Deafness and Other Communication Disorders grants R01DC00566 and P30DC04657 and the National Natural Science Foundation of China (31100799). We thank Nicole Arevalo, Jamie Costabile, Quang Dang, Gidon Felsen, Chelsea Gallegos, Tim Lei, and Nathan Schoppa.

The authors declare no competing financial interests.

Correspondence should be addressed to Diego Restrepo, Department of Cell and Developmental Biology, Neuroscience Program and Rocky Mountain Taste and Smell Center, University of Colorado Anschutz Medical Campus, Aurora, C0 80045. E-mail: diego.restrepo@ucdenver.edu.

DOI:10.1523/JNEUROSCI.3382-14.2014

Copyright $\odot 2014$ the authors $\quad 0270-6474 / 14 / 3416058-07 \$ 15.00 / 0$ sniffing (Wachowiak, 2011) and because of complex interactions between odorants and the epithelium (Schoenfeld and Cleland, 2005; Scott et al., 2014). Here we precisely controlled sensory input to the olfactory bulb $(\mathrm{OB})$ with blue light using a strain of mice in which channelrhodopsin-2 is expressed in all olfactory sensory neurons, and studied behavior and mitral/tufted $(\mathrm{M} / \mathrm{T})$ cell responses to light pulses simulating odor puffs that were not synchronized with sniffing.

\section{Materials and Methods}

Animals. OMP-hChR2V mice were produced by gene targeting. A $6 \mathrm{~kb}$ omp targeting vector (Bozza et al., 2004) was modified so that the coding sequence for OMP was replaced with a human codon optimized version of channelrhodopsin-2 (H134R); fused to Venus YFP (Nagai et al., 2002); followed by a floxed, self-excising neomycin resistance cassette (Bunting et al., 1999; Bozza et al., 2002). The targeting vector was electroporated into a 129S6 ES cell line and recombinant clones identified by long-range PCR. Chimeras were produced by aggregation using C57BL/6J embryos. The strain is maintained on a mixed 129/B6 background.

Mice were bred in the animal facilities of the University of Colorado Anschutz Medical Campus. We used male adult heterozygous OMPChR2 mice and wild-type C57BL/6 J mice. The animals were housed in a vivarium with a 14/10 h light/dark cycle with lights on at 10:00 P.M. Food (Teklad Global Rodent Diet no. 2918; Harlan) was available ad libitum. Access to water was restricted to the behavioral session; however, if mice did not obtain $\sim 1 \mathrm{ml}$ of water during the behavioral session, additional water was provided in a dish in the cage (Slotnick and Restrepo, 2005). All mice were weighed daily and received sufficient water during behavioral sessions to maintain $>80 \%$ of prewater restriction weight. All experiments were performed according to protocols approved by the University of Colorado School of Medicine Institutional Animal Care and Use Committee.

Slice preparation and recording. Horizontal slices $(300-400 \mu \mathrm{m})$ of the OBs of 1-month-old OMP-hChR2Vmice were viewed on a Zeiss Axioskop 2FS microscope. Light stimulation was performed with $200 \mathrm{~ms}$ pulses of laser activation $(473 \mathrm{~nm})$ through the objective. Experiments were performed at $32-35^{\circ} \mathrm{C}$ in Ringer's solution containing the following 
(in mM): $125 \mathrm{NaCl}, 25 \mathrm{NaHCO}_{3}, 1.25 \mathrm{NaH}_{2} \mathrm{PO}_{4}, 25$ glucose, $3 \mathrm{KCl}, 2$ $\mathrm{CaCl}_{2}$, and $1 \mathrm{MgCl}_{2}$, pH 7.3, oxygenated with $95 \% \mathrm{O}_{2}, 5 \% \mathrm{CO}_{2}$. Extracellular potential was recorded with $2-4 \mathrm{M} \Omega$ glass electrodes filled with the Ringer's solution.

Surgery for implantation of optotetrodes. Mice were briefly exposed to isoflurane $(2.5 \%)$ and subsequently anesthesia was maintained by intraperitoneal ketamine-xylazine injection (100 and $20 \mu \mathrm{g} / \mathrm{g}$, respectively) verified by toe pinch. On a stereotaxic device, the fur on the surface of the scalp from the midline of the orbits to the midpoint between the ears was removed and a hole was drilled above the left $\mathrm{OB}$ for optotetrode implant ( $4.0 \mathrm{~mm}$ anterior from bregma, $0.5 \mathrm{~mm}$ lateral from midline), and two screw holes were drilled into the parietal; one served as ground.

The optotetrodes included one glass tube for the optic fiber and four tetrodes that consisted of four polyamide-coated nichrome wires (diameter $12.5 \mu \mathrm{m}$; Sandvik) gold plated to an impedance of 0.2-0.4 M $\Omega$. Tetrodes were connected and the glass tube was glued through an EIB-16 interface board (Neuralynx). The optotetrodes were implanted targeting the mitral cell layer in the OB determined by M/T firing (depth: 1800$2200 \mu \mathrm{m}$; Doucette et al., 2011) and sealed to the bone by dental acrylic. Optotetrodes were implanted in nine mice.

In vivo electrophysiological recordings and light stimulation. During recording, the mouse was freely moving in a chamber $(11.6 \times 9.7 \times 9.4 \mathrm{~cm}$ deep). The signals recorded from the tetrodes were sent to a headstage (LP16CH; Tucker-Davis Technologies) and a 16-channel amplifier (Model 3500; A-M systems; bandpass $1-5000 \mathrm{~Hz} \times 2000$ gain), and were sampled at $24 \mathrm{kHz}$ by a DT3010 A/D card (Data Translation).

Light was delivered via a diode-pumped, solid-state laser $(473 \mathrm{~nm}$; Shanghai Laser \& Optics Century). The power was measured to be 19.5$21.5 \mathrm{~mW}$ for pulses 5-200 ms. Light stimulation was triggered by the recording program, which sent a signal to a stimulator (Master 8; A.M.P.I.). Temporal parameters included five light pulses per trial; and pulse duration was 10-200 ms. Light pulses were presented for 12 trials with an intertrial interval of $20 \mathrm{~s}, 60$ pulses for each duration. Light activation was not synchronized with sniff.

Cannula implant for light delivery in the behavioral mice. A cannula was implanted in the OB in six mice used to perform the light duration discrimination task, as described in Stubblefield et al. (2013). Briefly, after a hole was drilled on the skull, a steel guide/dummy cannula assembly (Plastics One) was targeted to the $\mathrm{OB}$ and fixed to the skull using two small screws and then glued with dental acrylic.

Behavioral tasks. After animals recovered from surgery (1-2 weeks) go-no-go behavioral training began following water deprivation (Doucette et al., 2011). In the odor discrimination task the animals learned to lick a tube for $2.5 \mathrm{~s}$ after presentation of a reinforced odor (S+; $1 \%$ phenyl acetate) and no lick for the unreinforced odor (S-; $1 \%$ 2-butanone). Light pulses replaced odors in the light-duration discrimination task. Both S+ and S- consist of 10 pulses of light, with intervals of $0.25 \mathrm{~s}$ and total duration of $2.5 \mathrm{~s}$. The only difference between $\mathrm{S}+$ and $\mathrm{S}-$ is the duration of each pulse, with S + always $100 \mathrm{~ms}$, and S-10-200 ms. The mouse was rewarded with water for licking on the tube for the $\mathrm{S}+$ odor/light. The animal's performance was evaluated in blocks of 20 trials (10 S + and $10 \mathrm{~S}-$ trials presented at random). When animals were introduced to discrimination between $100 \mathrm{~ms}$ and new light pulse duration (10-95 ms or 105-200 ms) they generally attained at least two blocks $>80 \%$ correct within one or two sessions. Animals were tested for at least three sessions if they did not attain the $80 \%$ correct for two blocks.

Off-line spike sorting and statistics. Tetrodes were inserted in the mitral cell layer where we detected voltage fluctuations significantly larger than when they were in the granule cell layer (Doucette et al., 2011, their Fig. S5). Raw electrophysiological data were bandwidth filtered (300-5000 $\mathrm{Hz}$ ) and spikes were sorted using Spike2 software (Cambridge Electronic Design). The data $100 \mathrm{~ms}$ before and $200 \mathrm{~ms}$ after the onset of each light stimulation were extracted, and the peristimulus time histogram (PSTH) was generated by averaging the spike-firing rate within bins of $5 \mathrm{~ms}$. For each light duration the data from 60 pulses were averaged.

To quantify and statistically test whether the responses to light were tonic or phasic we estimated the change in the firing rate $(\Delta$ firing rate $=$ light-evoked firing rate - firing rate of baseline). The firing rate of the baseline was calculated as the number of spikes in a window $100 \mathrm{~ms}$ before light on divided by $0.1 \mathrm{~s}$. To estimate whether the responses were tonic or phasic we used two approaches. In the first approach (time window approach) the light-evoked firing rate was calculated as the number of spikes divided by the seconds in a time window starting $25 \mathrm{~ms}$ after the light was turned on to $20,30,60,100$, and $200 \mathrm{~ms}$ later ( $\Delta$ time). If the response is phasic as in Figure $3 a$, there is a transient increase of the firing rate right after light on. In this case the $\Delta$ firing rate becomes smaller for the larger time windows, because to calculate the average the same number of spikes is divided by a larger $\Delta$ time (Fig. $3 c$ ). In addition, because the response is phasic there should not be a difference between different light-on durations because the spikes contributing to the $\Delta$ firing rate take place shortly after the light turns on (Fig. 3c). On the other hand, if a response is a tonic increase in the firing rate then in the larger time windows ( $\Delta$ time 100 and $200 \mathrm{~ms}$ ) then the $\Delta$ firing rate calculated should increase when light-on times increase because of a larger number of spikes contributed by a tonic response for longer light-on periods (100 and $200 \mathrm{~ms}$ time windows in Fig. 3d). Consistent with this, the lightinduced increases in firing rate were considered tonic if for the larger time windows the $\Delta$ firing rate for different light-on durations was significantly different tested with a one-way ANOVA $(p<0.05$; an example is shown in Fig. $3 d$ ). In the second approach, to consider whether the responses were tonic or phasic $(3 \times \mathrm{SD}$ approach) we counted the number of bins in the $200 \mathrm{~ms}$ after the light stimulation period that were above three times the SD in the $100 \mathrm{~ms}$ pre-light stimulation period. The number of these bins was then multiplied by $5 \mathrm{~ms}$ to yield the response time shown in Figure $3 f$ and $g$.

To evaluate responsiveness for Figure $3 e$ we compared the firing rate before ( $100 \mathrm{~ms}$ before light on, 20 bins) and after light stimulation (20$200 \mathrm{~ms}, 4-40$ bins) using a $t$ test $(p<0.05)$. Finally, Friedman two-way ANOVA was used to evaluate differences in the percentage of responsive units followed up by post hoc Tukey's HSD multiple-comparison test among proportions for different time windows in Figure $3 e$.

Monitoring pressure change during sniffing. Sniffing was monitored by recording intranasal pressure through an implanted nasal cannula connected to a pressure sensor (Model No. 24PCEFA6G(EA), 0-0.5 psi; Honeywell) via polyethylene tubing. As described in previous publications (Doucette et al., 2011; Gire et al., 2013a) surgical procedures for cannula implantation were based on the work of Wesson et al. (2008). Voltage recordings of pressure transients were amplified 100-fold using a 3000 amplifier from A-M systems, digitized using a DT3010 A/D card from Data Translation in a PC, and sampled at $24 \mathrm{kHz}$. Each sniff was detected as occurring at the point for the transition from exhalation to inhalation.

\section{Results}

\section{Light evoked response of putative mitral/tufted cells in slice recordings}

We took advantage of optogenetics using a novel strain of mice (OMP-hChR2V) in which the olfactory marker protein (OMP) promoter drives expression of a "humanized" (codon optimized) version of channelrhodopsin-2 fused to Venus YFP (Smear et al., 2011) to make it possible to activate olfactory sensory neuron (OSN) axons in the glomeruli of the OB using light.

To test how light activates the olfactory system we recorded extracellular voltage in an $\mathrm{OB}$ slice preparation. As shown in Figure $1 a$, ChR2-Venus, which is expressed in all mature OSNs, is found in their axonal nerve terminals in glomeruli of the OB. Light stimulation of the nerve terminals evokes obvious excitatory responses in the $\mathrm{M} / \mathrm{T}$ cells recorded as an increase in variance in the extracellular voltage in the mitral cell layer (Fig. 1b). Light pulses of $200 \mathrm{~ms}$ duration evoked robust responses at the initial stage of stimulation that dropped within the pulse, but still showed a prolonged response (Fig. $1 b$ ). To determine whether the excitatory responses observed above were through synaptic transmission as opposed to direct stimulation we blocked transmission from OSNs by applying antagonists NBQX and AP-5 for NMDA and AMPA receptors, respectively. These antagonists 
a
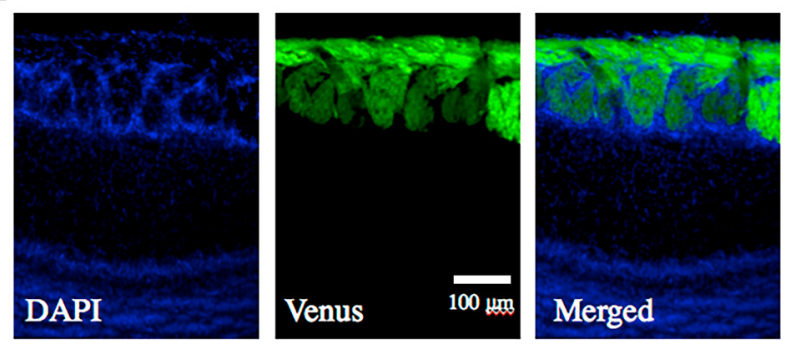

b

Control

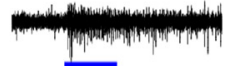

$\mathrm{NBQX}$ and AP5

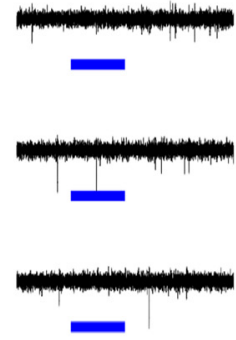

Wash
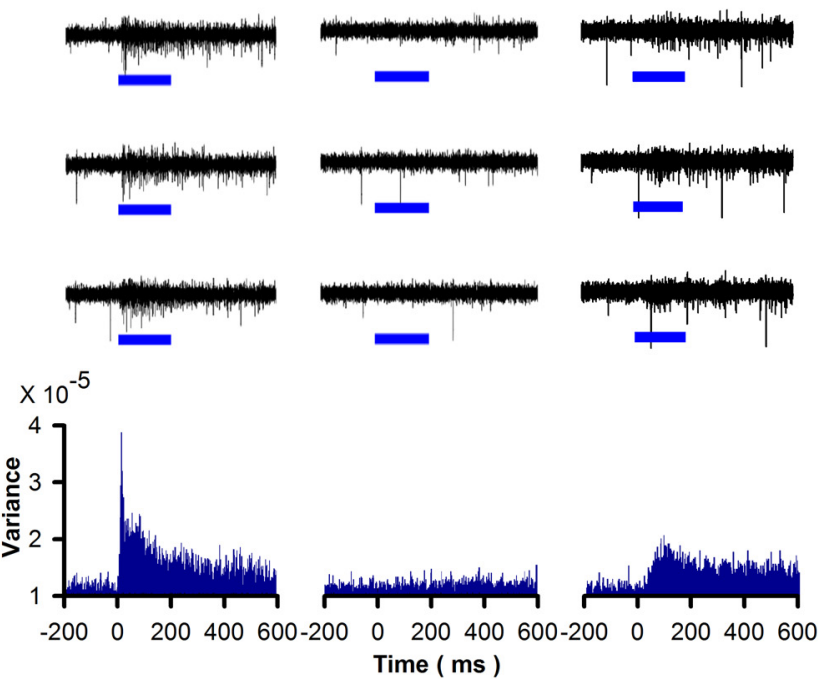

Figure 1. Light evoked extracellular voltage responses in the mitral cell layer of an $0 B$ slice. $\boldsymbol{a}$, Fluorescence image of the $0 B$. $\boldsymbol{b}$, Left, $200 \mathrm{~ms}$ of whole-field laser stimulation $(473 \mathrm{~nm})$ evokes robust extracellular voltage variation in the mitral cell layer caused by mitral cell spiking (data filtered from 300 to $4000 \mathrm{~Hz}$ ). b, Middle, Light-evoked action potentials are completely blocked by application of NBQX $(10 \mu \mathrm{m})$ and AP-5 $(100 \mu \mathrm{M}) . \boldsymbol{b}$, Right, The response partially recovers after washing with Ringer's solution. Top, Extracellular voltage traces. Blue bars represent light stimulation. Bottom, Variance of the extracellular voltage.

abolished the responses, indicating that light excitation of $\mathrm{M} / \mathrm{T}$ cells was mediated by postsynaptic activation.

\section{Response of mitral/tufted cells to different input durations in free-moving mice}

Tetrodes were used to record extracellular potential changes in the mitral cell layer of the $\mathrm{OB}$ in freely moving mice. Figure $2 a$ shows the optotetrode: tetrodes assembled with a glass tube to guide the optical fiber used to stimulate ChR2 expressed in the OSN axons in glomeruli. An example of the raw extracellular voltage signal filtered from 300 to $5000 \mathrm{~Hz}$ is shown in Figure $2 b$ and the spikes extracted from this signal using Spike2 software are shown in Figure $2 c$. Because odor puffs are expected to come in with timing dependent on odor release and turbulence and not odor sniffing, we used light pulses unsynchronized with sniffing to activate ChR2 (Fig. 2e). Examples of responses of neurons in the mitral cell layer are shown in Figure $2 d$. In free-moving mice light stimulation evoked largely excitatory responses (47/81, $58 \%)$ with only $14(17 \%)$ inhibitory responses. These results are somewhat comparable to the previous study with similar mice by Smear et al. (2011).

We tested how the M/T cells respond to light stimulation with different durations and we found phasic and tonic responses to light (Fig. 3). One example of an obvious phasic increase of firing rate that lasted $30-50 \mathrm{~ms}$ is shown in Figure $3 a$. We calculated the firing rate change $(\Delta$ firing rate $=$ post-light stimulation spikes pre-light stimulation spikes divided by different time window durations; see Materials and Methods). For this cell, light evoked significant firing rate increases for all light stimulation durations, but as expected, because of the phasic response for shorter time windows, a larger $\Delta$ firing rate was found (Fig. $3 c$ ). However, for any time window, no significant difference between $\Delta$ firing rate for different light durations could be found (one-way ANOVA, $p>0.05)$. In addition, we calculated the response time as the time encompassed by bins within $200 \mathrm{~ms}$ after light stimulation that exceeded the average pre-light stimulation firing rate plus 3 SDs of the pre-light stimulation firing rate $(3 \times \mathrm{SD})$. Consistent with a phasic increase in the firing rate this response time did not increase as a function of light-on duration (Fig. $3 f$, blue). Thus, the spike output from these units cannot be used to discriminate different input durations.

However, in other units optogenetic activation of ChR2 by light evoked tonic responses that lasted as long as light-on duration. For example, for the unit in Figure $3 b$ the average $\Delta$ firing rate calculated within time windows of $60-200 \mathrm{~ms}$ was significantly different for different durations of optogenetic light activation of the glomeruli (Fig. $3 d$; one-way ANOVA, $p<0.001$ ). Consistent with this the response time for firing rates above $3 \times$ SD calculated for this example increased linearly as a function of duration of light pulses (Fig. $3 f$, red). Thus, for this cell, different duration of glomerular activation by light could be discriminated by the total number of spikes within the time windows.

For all the M/T cells from which we recorded, with shorter durations $(10-30 \mathrm{~ms})$, the percentage of responsive cells decreased significantly compared with longer durations (100-200 $\mathrm{ms}$ ) in the larger time windows used for analysis (Fig. 3e, 100 and $200 \mathrm{~ms}$ ) consistent with a tonic response to the stimulus. This happens because with a tonic response the number of spikes fired above the prestimulus rate for short stimulation $(10-30 \mathrm{~ms}) \mathrm{de}-$ creases as the analysis window is increased to 100-200 ms. Indeed Friedman two-way ANOVA for the data in Figure $3 e$ indicated that there was a change in percentage responsive cells $\left(\chi^{2}=12\right.$, $p=0.02$ ), and subsequent post hoc Tukey's HSD multiplecomparison test reveals significant differences for a short time for light activation in long time windows used for analysis (Fig. $3 e$, ${ }^{\#} p<0.05$ ). In addition, Figure $3 g$ shows results from a complementary analysis showing that when all units with at least one bin above $3 \times \mathrm{SD}$ ( 21 of 81 units) were included the response time for firing rate above $3 \times$ SD increased linearly as a function of duration of light supporting an underlying capability of the olfactory system to perceive duration of input. Finally, calculating the mean light-induced $\Delta$ firing rate for all 81 units in the study showed a response that included an initial transient phase followed by a tonic response that carried information on light duration (Fig. $3 h$ ).

\section{Detection of glomerular input via optogenetic glomerular activation}

To test whether the mouse detects light stimulation, we performed a go-no-go experiment (Fig. $4 a, b$ ). First, the OMP-hChR2V mice were trained to discriminate between two odors (phenyl acetate vs 2-butanone; Fig. $4 c$ ). Then, the odors were replaced by optogenetic activation for $100 \mathrm{~ms}(\mathrm{~S}+)$ or no activation by light $(\mathrm{S}-)$. Figure $4 d$ shows that OMP-hChR2V mice were able to perceive light stimulation as a cue.

To control for use of light itself as a visual cue we performed go-no-go experiments with wild-type mice that were able to discriminate between odors but not between light and no light 


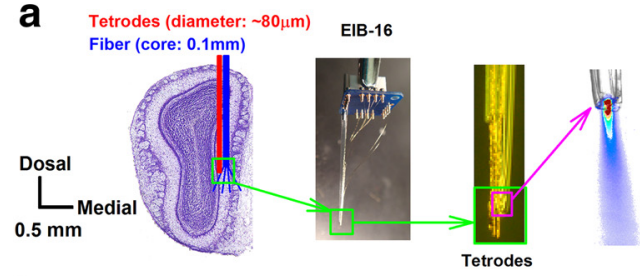

b
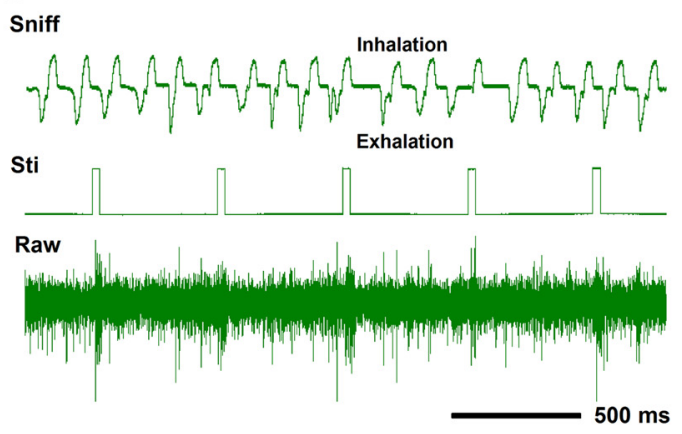

C

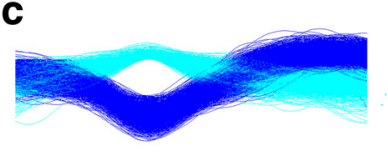

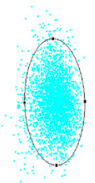

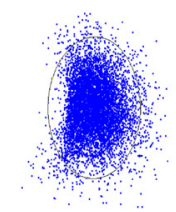

d
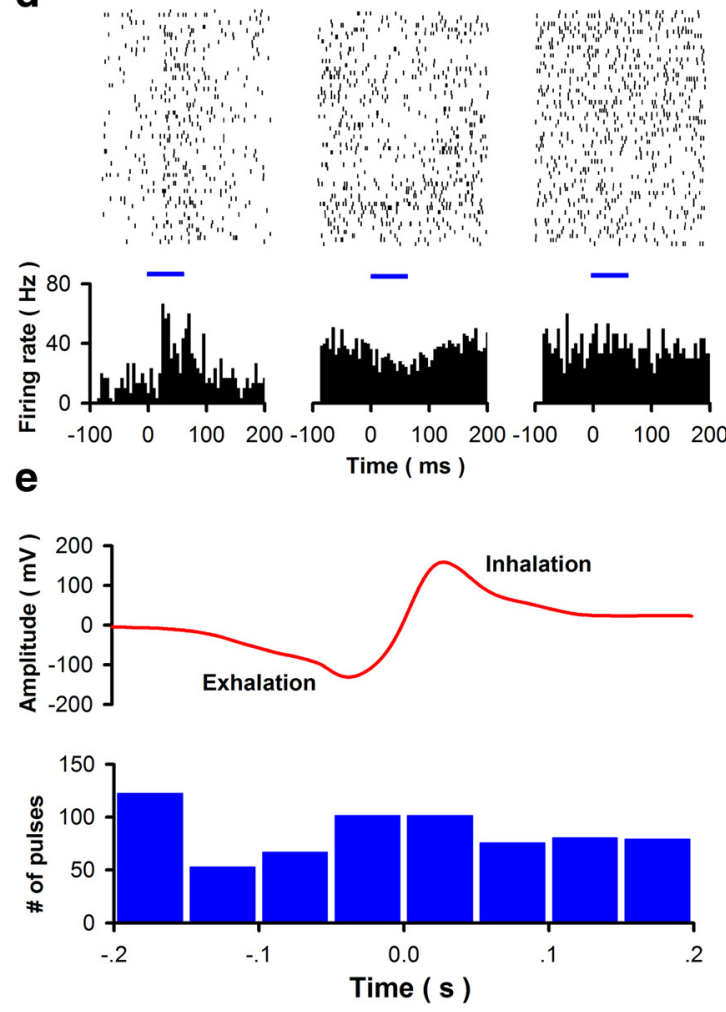

Figure 2. Recording of sniffs and extracellular voltage in the mitral cell layer and light-elicited stimulation of ChR2 expressed in the axons of 0SNs. $\boldsymbol{a}$, Optotetrodes. Left, The combination of a guide glass tube and tetrodes was inserted into the mitral cell layer of the $0 \mathrm{~B}$ to allow recording of M/T cell activity and light stimulation of glomerular ChR2. Center, View of the optotetrode attached to the EIB-16 electrode interface. Right, Higher magnification view of the tip of the tetrodes and the glass guide for the optic fiber. The tip of the tetrodes is $\sim 0.2-0.3 \mathrm{~mm}$ longer than the fiber. $\boldsymbol{b}$, Example of raw recording of extracellular potential and voltage changes recorded by the pressure sensor measuring nose pressure. Light was turned on at times shown by the trace labeled Sti. $c$, Two units separated from the data in $\boldsymbol{b}$ using Spike2 software. Left, Voltage variation for the two units. Right, Separation of the two units using principal component analysis. $\boldsymbol{d}$, Three examples of the effect of light stimulation on spike firing by M/Ts. From left to right: Excitatory response, inhibitory response, and no response. Above, Raster for 60 trials; below. PSTH. Blue bars represent light stimulation $(60 \mathrm{~ms})$. $\boldsymbol{e}$, Light pulses are not synchronized with the sniff. Top, Average voltage recording with the pressure sensor detecting pressure inside the nose for 681 sniffs taking place during light activation. Bottom, Bar graph showing the timing of light activation in the same time interval. A Rayleigh test for the significance of the mean direction in a histogram indicated that there was no specific distribution for this bar graph $(p>0.05)$.

(Fig. 4e,f). This indicates that OMP-hChR2V mice use light activation of the olfactory system as the cue to solve the behavioral task, rather than light detection via other modalities.

\section{Behavioral discrimination of duration of optogenetic activation of glomerular input}

We then tested whether mice were able to precisely discriminate different input durations (light durations). We used $100 \mathrm{~ms}$ light duration as $\mathrm{S}+$, since inhalation duration of one sniff is often $\sim 100 \mathrm{~ms}$ (Carey and Wachowiak, 2011; Doucette et al., 2011; Shusterman et al., 2011; Rojas-Líbano and Kay, 2012). For short S-, we used 10-95 ms durations and for long S-, we used 200105 ms durations. As an example in Figure $4 g$, for short $S-$, this mouse can discriminate between 90 and $100 \mathrm{~ms}$, showing discrimination of duration within $10 \mathrm{~ms}$. Also, for long $\mathrm{S}-$, it can discriminate between 100 and $110 \mathrm{~ms}$ (Fig. 3h). We trained six mice to discriminate different durations (Fig. 4i): two of them can discriminate within $10 \mathrm{~ms}$ and four within $20 \mathrm{~ms}$. The percentage correct responses for all light-on durations differ from the 95 and 105 ms light-on duration correct responses in an ANOVA followed up by a post hoc Tukey's HSD criterion $(p<$ 0.05 ). Therefore mice can discriminate light-on duration activating ChR2 within $10 \mathrm{~ms}$.

\section{Discussion}

Olfactory information encoded by OSNs is processed by the OB before transmission to upstream brain areas (Gire et al., 2013b; T.A. Cleland, 2014). Studies with invertebrates indicate that stimulus duration for puffs of odor perceived from odor plumes is a key temporal parameter that needs to be decoded by higher brain centers (Christensen and Hildebrand, 1997; Heinbockel et al., 1999; Cardé and Willis, 2008; Park et al., 2014). Taking advantage of optogenetic mice our study reveals that a subset of M/T cells respond tonically to direct activation of glomeruli thereby carrying information on stimulus pulse duration as the total number of spikes fired within a time interval. In addition, behaviorally the mice can discriminate stimulus duration with a resolution of 10 $\mathrm{ms}$ (they can differentiate $90 \mathrm{~ms}$ or $110 \mathrm{~ms}$ stimuli from $100 \mathrm{~ms}$ stimuli; Fig. 4i). The results provide evidence that precise perception of differences in the duration of input to glomeruli can be attained by the mammalian olfactory system, and that M/T cells transmit information on input duration for upstream brain processing.

Since our light stimulations were done without synchronization to sniffing, our data suggest that stimulus duration information can be faithfully encoded within the incoming phase of the sniff cycle. This makes sense ethologically. Inver- 

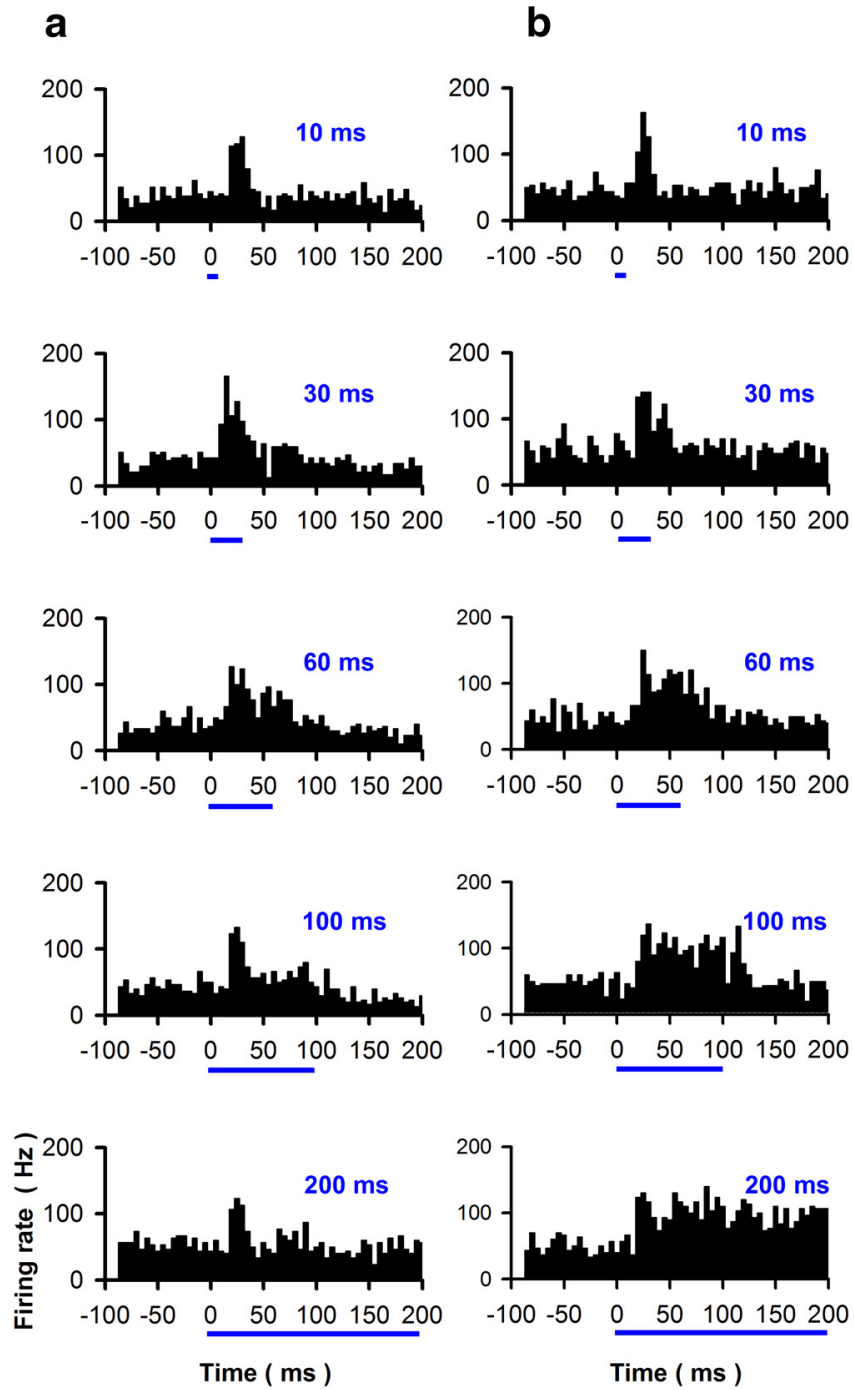

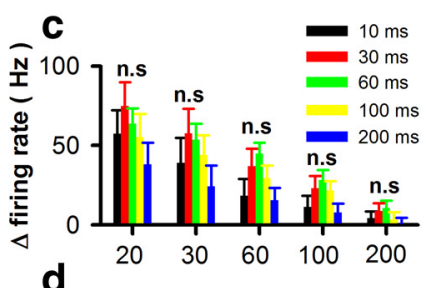

h
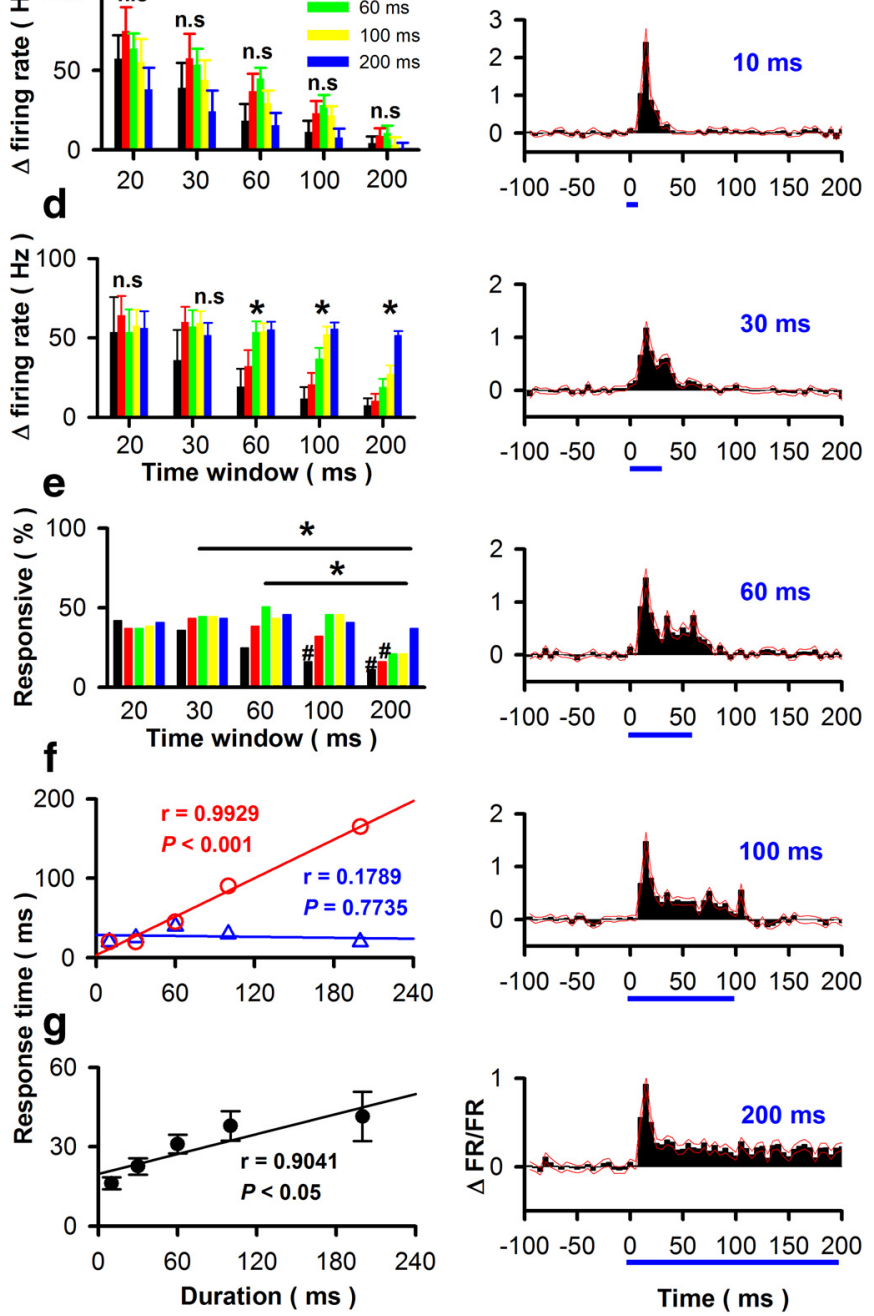

Figure 3. Some M/Ts in the OB display responses with information on the duration of the stimulus (duration-informative responses). $\boldsymbol{a}, \boldsymbol{b}$, Two representative M/Ts not showing ( $\boldsymbol{a}$ ) or showing (b) duration-informative responses. The blue bars represent light stimulation of the glomerular OSN input in 0MP-hChR2V mice. $\boldsymbol{c}, \boldsymbol{d}$, Firing rate changes in the cells displayed in $\boldsymbol{a}$ and $\boldsymbol{b}$ evoked by light stimulation with different durations shown for different time windows used to calculate an average change in the firing rate. One-way ANOVA for duration of the light stimulus: $\mathrm{n} . \mathrm{s}, \mathrm{p}>0.05$. One-way ANOVA for the time window $F=77$ in c and 8 in $\boldsymbol{d}, p<0.001$. e, Percentage of responsive M/Ts (significant firing changes after light stimulation) for different light durations and different time windows for all experiments ( $n=81$ for each light duration/time window). Friedman two-way ANOVA yielded $\chi^{2}=12, p=0.02$ for statistic difference between time windows (asterisk shows post hoc significant difference between time windows). Post hoc Tukey's HSD multiple-comparison test reveals significant differences ( ${ }^{~} p<0.05$ ). $f$, Duration of the response (response time) calculated as the time occupied by bars higher than average firing before light stimulation plus 3xSD plotted as a function of light pulse duration (duration). Blue, response time calculated for the data in $\boldsymbol{a}$; red, response time calculated for the data in $\boldsymbol{b} . \boldsymbol{g}$, Duration of the response (response time) calculated as the time occupied by bars higher than average firing before light stimulation plus 3 SDs plotted as a function of light pulse duration (duration) calculated for all the data. Only units for which at least one bar was above background plus $3 \times$ SD were included ( 21 of 81 units). Shown is average \pm SD. The correlation coefficient $(r)$ and the $p$ value for its difference from zero are shown in $\boldsymbol{f}$ and $\boldsymbol{g}$. $\boldsymbol{h}$, Mean change in firing rate for all units recorded from normalized by dividing by the firing rate before stimulation with light $(n=81)$.

tebrates can encounter brief pulses of odor (Cardé and Willis, 2008; Park et al., 2014), and these pulses may contain valuable information about odor location, concentration, or identity (Cardé and Willis, 2008; Park et al., 2014). Studies on the ability of mammals to detect spatiotemporal information in odor plumes are scarce. Recent work indicates that mice can detect with high precision (within $10 \mathrm{~ms}$ ) the timing of the stimulus with respect to the sniff cycle (sniff phase; Smear et al., 2011) and that mice use the spatiotemporal distribution of odor cues sampled in multiple sniffs to locate odor sources (D. Gire, unpublished observations). Our data indicate that mammals, like insects, may be able to detect rapid changes in odor plumes regardless of when they take place during intermittent stimulus sampling.
But how would time duration of an odor puff be modified as the odor is sampled by the sniff? In mammals, the internal factors that modify time representation of external stimulus duration are timing of sniffing, which is modified by the animal for active sampling, and the complex interaction between odorants and the mucus layer overlaying the OSNs (Schoenfeld and Cleland, 2005; Carey and Wachowiak, 2011; Wachowiak, 2011). On one hand, sniffing controls the access of olfactory stimuli to the OSNs, and the inhalation-driven OSN responses are transient, with each inhalation evoking a burst of OSN activity lasting only 100-200 ms (Uchida and Mainen, 2003; Kepecs et al., 2006; Carey and Wachowiak, 2011; Wachowiak, 2011). Because of this odor puffs shorter than sniff input will likely be maintained, but long puffs will be broken. 
a
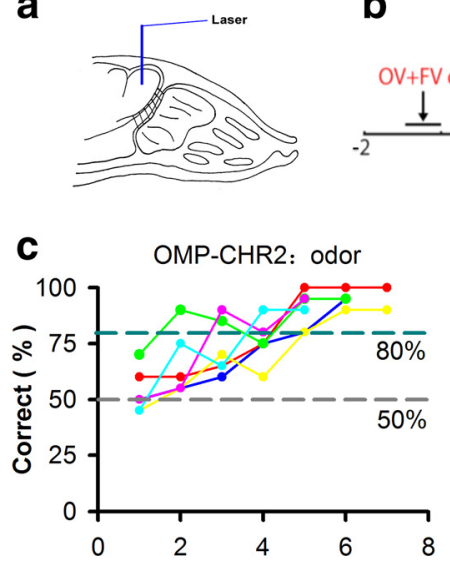

e

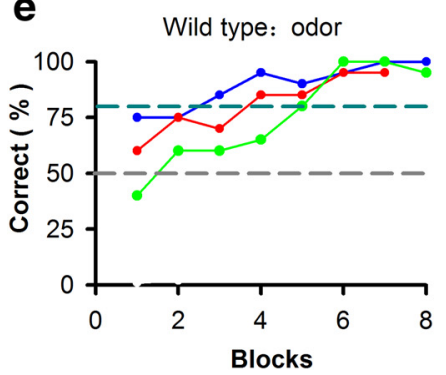

b

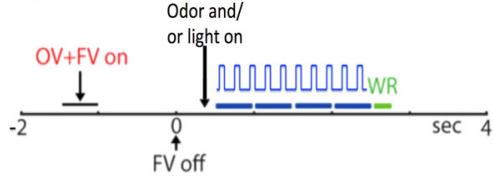

d

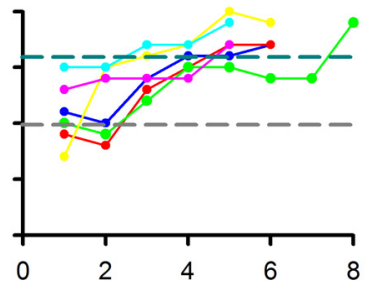

f

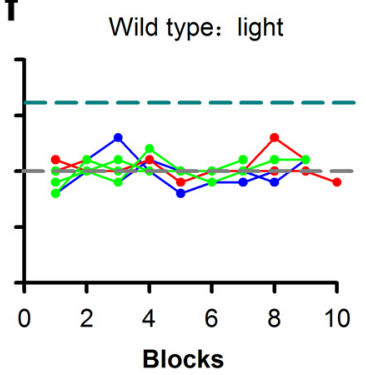

g

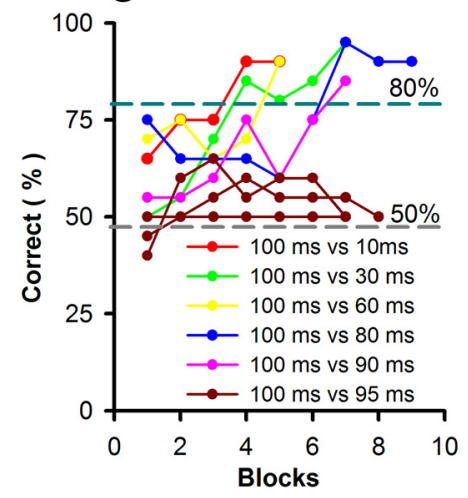

h
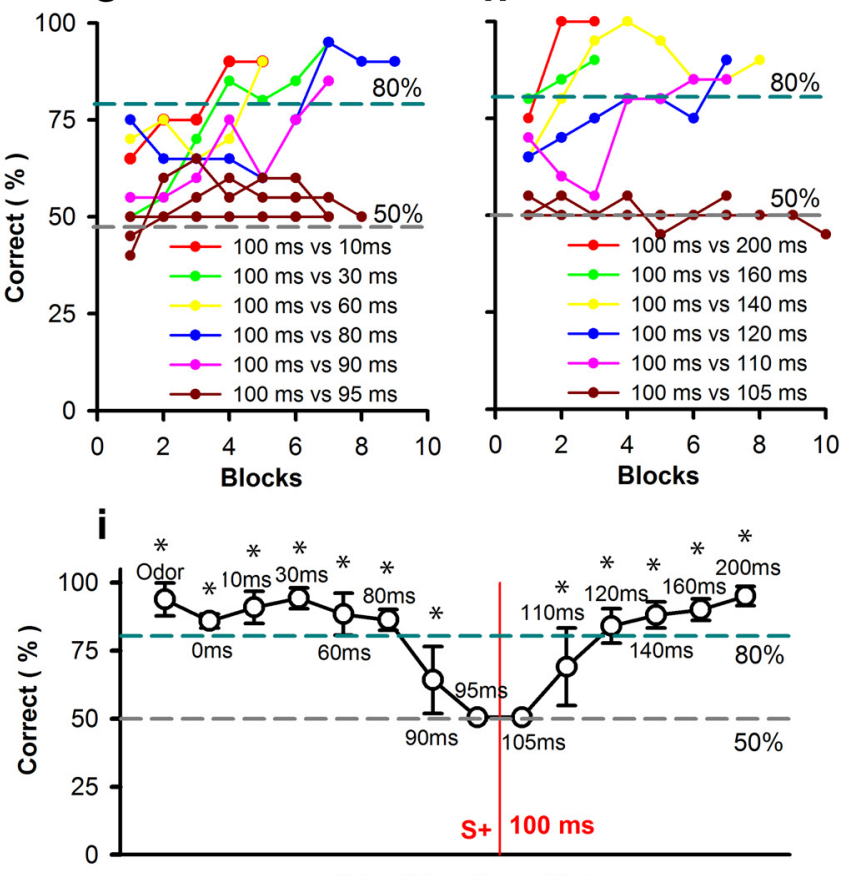

Odor / Duration of light

Figure 4. Animal performance in go—no-go odor discrimination or optogenetic discrimination tasks. $\boldsymbol{a}$, Schematic of cannula implant for light delivery. The cannula was implanted in the $\mathrm{OB}$ to stimulate a subset of ventral glomeruli. $\boldsymbol{b}$, Time course for trials in the odor discrimination or optogenetic discrimination tasks. $\mathrm{OV}$, olfactory valve; $F \mathrm{~F}$, final valve; $\mathrm{RA}$, response area; WR, water reward. OV and FA were only used for the odor discrimination task, not for the optogenetic discrimination task. Light is applied as a train of pulses (10 pulses; interval, $250 \mathrm{~ms}$; pulse duration from 10 to $200 \mathrm{~ms}$ ). c, Percentage correct for go-no-go odor discrimination as a function of block number for six 0MP-hChR2V mice. In each block the animal was exposed in 10 trails to the rewarded $(S+)$ odor (1\% phenyl acetate) and 10 trials to the unrewarded $(S-)$ odor (1\% 2-butanone). Different colors show the results for different mice. $d$, Percentage correct for go - no-go sessions with rewarded stimulus of optogenetic activation of glomeruli by light ( $\mathrm{S}+$, light pulses with $100 \mathrm{~ms}$ duration) and the unrewarded stimulus was no activation by light (S-).e, $\boldsymbol{f}$, Go - no-go for odor discrimination (e) or for optogenetic light activation $(\boldsymbol{f})$ for three (57BL/6 mice. $\boldsymbol{g}$, Discrimination of $100 \mathrm{~ms}$ pulses ( $\boldsymbol{S}+$ ) and shorter durations ( $(-, 10-95 \mathrm{~ms})$ for a representative mouse. $\boldsymbol{h}$, Discrimination of $100 \mathrm{~ms}$ pulses $(\boldsymbol{S}+)$ and longer durations ( $\mathrm{S}-, 200-105 \mathrm{~ms})$ for the same mouse. Two dashed lines show 50 and $80 \%$ correct responses, respectively. $i$, Percentage correct response for the last two blocks of sessions with $100 \mathrm{~ms}$ light pulse duration for the $S+$ stimulus and different light durations for the $S-$ stimulus (average $\pm S D, n=6$ ). These points $(*)$ differ from the 95 and 105 ms points in an ANOVA followed up by a post hoc Tukey's HSD criterion $(p<0.05$ ).

On the other hand, odor sorptiveness, controlled by factors such as odor hydrophobicity, imposes physicochemical constraints on transmission of odor from air through the mucus to the OSNs during inhalation, and the nonuniform distributions of OSN populations along the inhalation axis may enable sorptiveness to modify odor representations by affecting the number of molecules reaching different receptors during a sniff (Schoenfeld and Cleland, 2005; Cenier et al., 2013; Wei et al., 2013; Scott et al., 2014). The perception of time duration for odor puffs will likely change so that the temporal shape of the puff will be modified by essentially a convolution with the incoming air flow phase of the sniff restructuring the shape of the puff as a function of time.

For olfaction, temporal information can be an important cue for finding the odor source in a nature scene (Cardé and Willis, 2008; Park et al., 2014). For neural coding, temporal information carried by neuron firing spikes in the invertebrate olfactory system is critical for encoding the odorant (Stopfer et al., 1997; Laurent, 2002; Perez-Orive et al., 2002) and in the moth information on odor duration is encoded by macroglomerular complex antennal lobe projection neurons (Christensen and Hildebrand, 1997). In mammals, temporal information from internasal timing differences (Rajan et al., 2006) can be used as directional cues (Gottfried, 2005; Porter et al., 2005; Rajan et al., 2006; Arzi and Sobel, 2010; Gardiner et al., 2014). In addition, detection of the specific phase of the stimulus within the sniff has been found to be an important stimulus timing parameter that mice can use to make behavioral decisions with $10 \mathrm{~ms}$ precision (Smear et al., 2011). In the OB of mammals, the firing pattern of $\mathrm{M} / \mathrm{T}$ cells, such as sniff-locked spikes and theta- and gamma-correlated spikes, is also considered as an important cue for olfactory encoding (David et al., 2009; Cury and Uchida, 2010; Shusterman et al., 2011; Gschwend et al., 2012; Gire et al., 2013b; Narikiyo et al., 2014). We provide new data showing that tonically activated M/T cells can convey information about odor duration that is not synchronized to the sniff cycle.

Duration is a key parameter for sensory stimuli (B.G. Cleland et al., 1971; Ikeda and Wright, 1974; Ehrlich et al., 1997; Klink and Klump, 2004). For example, mice detect behaviorally an increment of auditory signal duration by $\sim 20 \%$ (Klink and Klump, 2004). Our duration discrimination behavior experiment yielded similar results in the olfactory system. Importantly, in both the inferior colliculus and primary auditory cortex, neurons have been identified that respond to specific durations (Ehrlich et al., 1997). In the olfactory system we also find some tonically responding $\mathrm{M} / \mathrm{T}$ cells that transmit information on different glomerular input durations and that animals detect duration of direct activation of glomeruli suggesting that mice may be able to take a "snapshot" of brief fluctuations in odor plumes (odor puffs). 


\section{References}

Arzi A, Sobel N (2010) Spatial perception: time tells where a smell comes from. Curr Biol 20:R563-R564. CrossRef Medline

Bozza T, Feinstein P, Zheng C, Mombaerts P (2002) Odorant receptor expression defines functional units in the mouse olfactory system. J Neurosci 22:3033-3043. Medline

Bozza T, McGann JP, Mombaerts P, Wachowiak M (2004) In vivo imaging of neuronal activity by targeted expression of a genetically encoded probe in the mouse. Neuron 42:9-21. CrossRef Medline

Bunting M, Bernstein KE, Greer JM, Capecchi MR, Thomas KR (1999) Targeting genes for self-excision in the germ line. Genes Dev 13:1524-1528. CrossRef Medline

Cardé RT, Willis MA (2008) Navigational strategies used by insects to find distant, wind-borne sources of odor. J Chem Ecol 34:854-866. CrossRef Medline

Carey RM, Wachowiak M (2011) Effect of sniffing on the temporal structure of mitral/tufted cell output from the olfactory bulb. J Neurosci 31: 10615-10626. CrossRef Medline

Cenier T, McGann JP, Tsuno Y, Verhagen JV, Wachowiak M (2013) Testing the sorption hypothesis in olfaction: a limited role for sniff strength in shaping primary odor representations during behavior. J Neurosci 33:79-92. CrossRef Medline

Christensen TA, Hildebrand JG (1997) Coincident stimulation with pheromone components improves temporal pattern resolution in central olfactory neurons. J Neurophysiol 77:775-781. Medline

Cleland BG, Dubin MW, Levick WR (1971) Sustained and transient neurones in the cat's retina and lateral geniculate nucleus. J Physiol 217:473496. Medline

Cleland TA (2014) Construction of odor representations by olfactory bulb microcircuits. Prog Brain Res 208:177-203. CrossRef Medline

Cury KM, Uchida N (2010) Robust odor coding via inhalation-coupled transient activity in the mammalian olfactory bulb. Neuron 68:570-585. CrossRef Medline

David FO, Hugues E, Cenier T, Fourcaud-Trocmé N, Buonviso N (2009) Specific entrainment of mitral cells during gamma oscillation in the rat olfactory bulb. PLoS Comput Biol 5:e1000551. CrossRef Medline

Doucette W, Gire DH, Whitesell J, Carmean V, Lucero MT, Restrepo D (2011) Associative cortex features in the first olfactory brain relay station. Neuron 69:1176-1187. CrossRef Medline

Ehrlich D, Casseday JH, Covey E (1997) Neural tuning to sound duration in the inferior colliculus of the big brown bat, Eptesicus fuscus. J Neurophysiol 77:2360-2372. Medline

Frasnelli J, Wohlgemuth C, Hummel T (2006) The influence of stimulus duration on odor perception. Int J Psychophysiol 62:24-29. CrossRef Medline

Gardiner JM, Atema J, Hueter RE, Motta PJ (2014) Multisensory integration and behavioral plasticity in sharks from different ecological niches. PLoS One 9:e93036. CrossRef Medline

Gire DH, Whitesell JD, Doucette W, Restrepo D (2013a) Information for decision-making and stimulus identification is multiplexed in sensory cortex. Nat Neurosci 16:991-993. CrossRef Medline

Gire DH, Restrepo D, Sejnowski TJ, Greer C, De Carlos JA, LopezMascaraque L (2013b) Temporal processing in the olfactory system: can we see a smell? Neuron 78:416-432. CrossRef Medline

Gottfried JA (2005) A truffle in the mouth is worth two in the bush: odor localization in the human brain. Neuron 47:473-476. CrossRef Medline

Gschwend O, Beroud J, Carleton A (2012) Encoding odorant identity by spiking packets of rate-invariant neurons in awake mice. PLoS One 7:e30155. CrossRef Medline

Heinbockel T, Christensen TA, Hildebrand JG (1999) Temporal tuning of odor responses in pheromone-responsive projection neurons in the brain of the sphinx moth Manduca sexta. J Comp Neurol 409:1-12. CrossRef Medline

Ikeda H, Wright MJ (1974) Evidence for "sustained" and "transient" neurones in the cat's visual cortex. Vision Res 14:133-136. CrossRef Medline

Kepecs A, Uchida N, Mainen ZF (2006) The sniff as a unit of olfactory processing. Chem Senses 31:167-179. CrossRef Medline

Klink KB, Klump GM (2004) Duration discrimination in the mouse (Mus musculus). J Comp Physiol A Neuroethol Sens Neural Behav Physiol 190:1039-1046. CrossRef Medline

Laurent G (2002) Olfactory network dynamics and the coding of multidimensional signals. Nat Rev Neurosci 3:884-895. CrossRef Medline

Nagai T, Ibata K, Park ES, Kubota M, Mikoshiba K, Miyawaki A (2002) A variant of yellow fluorescent protein with fast and efficient maturation for cell-biological applications. Nat Biotechnol 20:87-90. CrossRef Medline

Narikiyo K, Manabe H, Mori K (2014) Sharp wave-associated synchronized inputs from the piriform cortex activate olfactory tubercle neurons during slow-wave sleep. J Neurophysiol 111:72-81. CrossRef Medline

Park IM, Bobkov YV, Ache BW, Príncipe JC (2014) Intermittency coding in the primary olfactory system: a neural substrate for olfactory scene analysis. J Neurosci 34:941-952. CrossRef Medline

Perez-Orive J, Mazor O, Turner GC, Cassenaer S, Wilson RI, Laurent G (2002) Oscillations and sparsening of odor representations in the mushroom body. Science 297:359-365. CrossRef Medline

Porter J, Anand T, Johnson B, Khan RM, Sobel N (2005) Brain mechanisms for extracting spatial information from smell. Neuron 47:581-592. CrossRef Medline

Rajan R, Clement JP, Bhalla US (2006) Rats smell in stereo. Science 311: 666-670. CrossRef Medline

Rojas-Líbano D, Kay LM (2012) Interplay between sniffing and odorant sorptive properties in the rat. J Neurosci 32:15577-15589. CrossRef Medline

Schoenfeld TA, Cleland TA (2005) The anatomical logic of smell. Trends Neurosci 28:620-627. CrossRef Medline

Scott JW, Sherrill L, Jiang J, Zhao K (2014) Tuning to odor solubility and sorption pattern in olfactory epithelial responses. J Neurosci 34:20252036. CrossRef Medline

Shusterman R, Smear MC, Koulakov AA, Rinberg D (2011) Precise olfactory responses tile the sniff cycle. Nat Neurosci 14:1039-1044. CrossRef Medline

Slotnick BM, Restrepo D (2005) Olfactometry with mice. In: Current protocols in neuroscience (Crawley JN, Gerefen CR, Rogawski MA, Sibley DR, Skolnick P, Wray S, eds), pp 1-24. New York: Wiley.

Smear M, Shusterman R, O'Connor R, Bozza T, Rinberg D (2011) Perception of sniff phase in mouse olfaction. Nature 479:397-400. CrossRef Medline

Stopfer M, Bhagavan S, Smith BH, Laurent G (1997) Impaired odour discrimination on desynchronization of odour-encoding neural assemblies. Nature 390:70-74. CrossRef Medline

Stubblefield EA, Costabile JD, Felsen G (2013) Optogenetic investigation of the role of the superior colliculus in orienting movements. Behav Brain Res 255:55-63. CrossRef Medline

Uchida N, Mainen ZF (2003) Speed and accuracy of olfactory discrimination in the rat. Nat Neurosci 6:1224-1229. CrossRef Medline

Wachowiak M (2011) All in a sniff: olfaction as a model for active sensing. Neuron 71:962-973. CrossRef Medline

Wei Z, Xu Z, Li B, Xu F (2013) Numerical simulation of airway dimension effects on airflow patterns and odorant deposition patterns in the rat nasal cavity. PLoS One 8:e77570. CrossRef Medline

Wesson DW, Donahou TN, Johnson MO, Wachowiak M (2008) Sniffing behavior of mice during performance in odor-guided tasks. Chem Senses 33:581-596. CrossRef Medline 